\title{
ADOLESCENT PREGNANCY; A COMPARATIVE STUDY FROM THE TEACHING HOSPITAL OF LAHORE, PAKISTAN
}

1. MBBS, FCPS.

Senior Registrar Gynae Department Jinnah Hospital, Lahore

2. MBBS, FCPS.

Senior Registrar Gynae Department Madina Teaching Hospital, Faisalabad

Correspondence Address:

Dr. Anees Fatima

Senior registrar Gynae Department Madina Teaching Hospital Faisalabad aneesfatima81@hotmail.com

Article received on:

12/04/2016

Accepted for publication:

30/05/2016

Received after proof reading:

$26 / 05 / 2016$

\section{Dr. Quddsia Tanveer ${ }^{1}$, Dr. Anees Fatima ${ }^{2}$}

ABSTRACT... Objectives: To compare the obstetric outcomes in adolescent and adult primigravida. Study Design: A comparative, cross sectional study. Setting: Gynae unit 3, Jinnah hospital, Lahore. Period: One year from Jan-Dec 2014. Methodology: Study population was adolescent primigravida ( $<19$ years) and adult primigravida between the ages $20-29$ years, 250 in each group who were $\geq 24$ weeks of gestation. Obstetric complications were recorded as percentages of anaemia, pre-eclampsia, antepartum hemorrhage, postpartum hemorrhage, gestational diabetes mellitus, preterm delivery, instrumental delivery, cesarean section rate, low birth weight, Apgar score $<7$ at 5 minutes and NNU admission. Data was entered into SPSS 16. Chi square test applied and a $p$-value of $\leq 0.05$ was considered significant. Results: The mean age of adolescent group was $18.4+0.56$ years while it was $24+2.47$ years in adult primigravida. The data revealed that the adolescent mothers are at higher risk of certain obstetric risks when compared to adult primigravida. These include anaemia ( $41.2 \%$ VS 17.6\%), pregnancy induced hypertension (14.4\% VS 1.6\%), preterm delivery (21.6\% VS 13.6\%), instrumental delivery $(6.4 \%$ VS $1.6 \%)$, cesarean section rate (24\% VS 12\%), low birth weight (20.4\% VS $8 \%)$, Apgar score $<7$ at 5 minutes (4\% VS 2\%) and NNU admission (19.2\% VS $8 \%$ ). The risk of antepartum hemorrhage (1.6\% VS 1.2\%), postpartum hemorrhage (0.8\% VS $1.6 \%)$, gestational diabetes mellitus (1.2\% VS $2 \%$ ) and malpresentation (1.6\% VS $2 \%$ ) were not different in two groups. Conclusion: Adolescent pregnancy is associated with a higher rates of certain obstetric risks like anemia, preterm delivery, pregnancy induced hypertension, instrumental delivery, cesarean section and poor neonatal outcome However the risk of antepartum hemorrhage, postpartum hemorrhage and malpresentation is no greater than adult pregnant mothers.

Key words: Adolescent pregnancy, outcome.

Article Citation: Tanveer Q, Fatima A. Adolescent pregnancy; a comparative study from the teaching hospital of Lahore, Pakistan. Professional Med J 2016;23(6):727730. DOI: 10.17957/TPMJ/16.3128

\section{Novelty}

There is an increase in the reproductive and sexual health risks among the adolescents worldwide. The problem is even worse and inadequately addressed in developing countries like Pakistan. The published evidence on pregnant adolescent girls is inconclusive and contradictory at many points. Our study will contribute significantly in better understanding of snags among adolescent mothers. It will also help in signifying the need for women education, improved obstetric and contraceptive facilities so that the complications of adolescent pregnancies can be battled in a better mode.

\section{INTRODUCTION}

Adolescence refers to a transitional period of physical and mental human development, involving biological, social and psychological modifications that occur between 10-19 years of age. ${ }^{1}$ A fifth of world's population consists of adolescents with the number exceeding a billion and rising further particularly in developing nations. ${ }^{2}$ Adolescent pregnancy is the one that occurs after menarche to age of nineteen. ${ }^{3}$ Pakistan is carrying 7th number among ten countries with the highest numbers of women between 20 to 24 years of age who have had a live birth before reaching the age of eighteen. ${ }^{4}$ Teenage pregnancy carries some worrisome social and medical complications not only to the mother but to the offspring as well. It may also add to the progression of poverty and its added problems. ${ }^{5,6}$ Teenage pregnancies are frequently 
complicated by hyperemesis gravidarum, miscarriage, malaria, anaemia, preeclampsia, eclampsia, and prematurity. The complications of labor include obstructed labor due to fetopelvic disproportion, rupture uterus, stillbirth, obstetric fistulae, prolonged labor, instrumental delivery, caesarean section, and death. ${ }^{3,7,8}$ The problem of adolescent pregnancy needs to be addressed with a multidimensional attitude. The burden of adolescent pregnancy problems can be reduced by widespread education about contraception which also involves provision of readily available, safe and appropriate contraceptive methods. Moreover, women specifically and the society in general require education about the problems encountered by teenagers not only during pregnancy but also in the child - raising. There is a definite need of counselling of the target groups about the importance of antenatal care and emergency obstetric services should be universally offered and freely reachable to manage such pregnancies optimally. . $^{3,9}$

Aim of this study was to compare the obstetric outcomes in adolescent mothers with those of adult mothers between ages 20-29 years attending a tertiary care hospital.

\section{METHODOLOGY}

The study was conducted from Jan 2014 to Dec 2014 at the Ob/Gyn unit III, Jinnah hospital, Lahore. 500 patients carrying single alive fetus at $\geq 24$ weeks of gestation were included in the study comprising 250 of adolescent (<19years) primigravida (group 1) and 250 of adult (2029 years) primigravida (group 2). The sampling technique was convenient non probability. Patients having medical disorders before pregnancy (on the basis of history), and fetal congenital anomalies (diagnosed on ultrasound) were excluded from the study. The data was collected on specially designed proforma. Observations such as maternal age, booking status, marital status, anemia $(\mathrm{Hb}<11 \mathrm{~g} \%)$, preterm delivery(delivery before 37 weeks of gestation), pregnancy induced hypertension(on the basis of history and examination), malpresentation( examination and ultrasound), antepartum hemorrhage(history and examination), instrumental delivery, cesarean section and postpartum hemorrhage(examination based). Neonatal observations included Apgar score $<7$ at 5 -minute, low birth weight $(<2.5 \mathrm{~kg})$ and NNU admission. Percentages were calculated for the above except maternal age for which mean $\pm S D$ were calculated for both groups. Chi square test was used for qualitative variables to assess any difference between the two groups. A p-value of $\leq 0.05$ was considered significant.

\section{RESULTS}

The mean ages in group -1 group-2 were $18.4+0.56$ years and $24+2.47$ years respectively. $65.6 \%(n=164)$ of group-1 women while $50.4 \%$ $(n=126)$ of group-2 women were un booked. Anaemia was seen in $41.2 \%(n=103)$ of group-1 while $17.6 \%(n=44)$ of group-2 cases. $14.4 \%$ $(n=36)$ of group -1 had pregnancy induced hypertension $(\mathrm{PIH})$ while this percentage was $1.6 \%(n=4)$ in group-2. Preterm delivery was observed in $21.6 \%(n=54)$ of group-1 while $13.6 \%(n=34)$ of group- 2 cases. The table shows the percentages of other variables like gestational diabetes mellitus (GDM), malpresentation, antepartum hemorrhage (APH), instrumental vaginal delivery, cesarean section, postpartum hemorrhage (PPH), low birth weight, low Apgar score and admission in neonatal unit among the two groups and their level of significance.

\begin{tabular}{|c|c|c|c|}
\hline Variable & $\begin{array}{c}\text { Group-1 } \\
N(\%)\end{array}$ & $\begin{array}{c}\text { Group-2 } \\
\text { N (\%) }\end{array}$ & p-value \\
\hline Un booked cases & $164(65.6)$ & $126(50.4)$ & 0.0007 \\
\hline Anemia & $103(41.2)$ & $44 \quad(17.6)$ & 0.0001 \\
\hline Preterm delivery & $54(21.6)$ & $34 \quad(13.6)$ & 0.0006 \\
\hline PIH & $36(14.4)$ & $4 \quad(1.6)$ & $<0.0001$ \\
\hline GDM & $3(1.2)$ & (2) & 0.371 \\
\hline APH & $4(1.6)$ & $3 \quad(1.2)$ & 0.56 \\
\hline Malpresentation & $4(1.6)$ & $5 \quad(2)$ & 0.65 \\
\hline Instrumental delivery & $16(6.4)$ & $4 \quad(1.6)$ & $<0.0001$ \\
\hline Cesarean section & $60(24)$ & $30(12)$ & $<0.0001$ \\
\hline PPH & $2(0.8)$ & $4 \quad(1.6)$ & 0.317 \\
\hline Low birth weight & $51(20.4)$ & $20(8)$ & $<0.0001$ \\
\hline Apgar $<7$ at $5-\mathrm{min}$ & $10(4)$ & $5 \quad(2)$ & 0.025 \\
\hline NNU admission & $48(19.2)$ & $20(8)$ & $<0.0001$ \\
\hline
\end{tabular}

Table-I. Comparison among obstetric outcome of adolescent and adult primigravida. 


\section{DISCUSSION}

Adolescent pregnancy problems are global, both in the high income as well as low income nation. The association of adolescent pregnancy with a variety of adverse fetomaternal outcomes makes it a high risk one. There are complex reasons for the poor outcome ranging from medical aspects to the communal and traditional reasons. More over there is dearth of general health care facilities and lack of provision of adequate contraception adds fuel to the fire in such compromised circumstances prevalent in the developing world. ${ }^{5,9}$

The majority of cases were un-booked in both groups but this percentage was higher in adolescent pregnancies. This finding correlate with that of $\mathrm{Naz} \mathrm{S}$ et al..$^{10}$ All the patients in both group were married. This finding differed from western studies due to variances in socio cultural tendencies. Current study showed that adolescent pregnancies are at higher risk of anemia $(41.2 \%$ VS 17.6\%). Talawar $S$ et al coated this risk as $30 \%$ VS $14 \% .{ }^{11}$ This finding is also consistent with the one described by Qazi G. ${ }^{1}$ Risk of preterm delivery was also higher in adolescent pregnancies (21.6\% VS 13.6\%) which correlate with the one observed by Derme $\mathrm{M}$ et al. ${ }^{12} \mathrm{PIH}$ was also higher in group-1 compared to adult group (14.4\% VS $1.6 \%)$. This observation is supported by Ayuba II et al and others. ${ }^{1,8,13}$ Percentage of GDM was $1.2 \%$ VS $2 \%$ in our study which correlate with a study conducted by Onoh RC et al. ${ }^{13}$ The percentages for malpresentation, APH, PPH were not different statistically among the two groups which is supported by studies conducted by Mukhopadhyay $\mathrm{P}$ et al, Punn KD et al and Shah $\mathrm{N}$ et al respectively. ${ }^{2,5,15}$ Instrumental delivery was commoner among adolescent pregnancies $(6.4 \%$ VS 1.6\%). Supporting this, Mukhopadhyay P et al observed similar trend in their study. ${ }^{5}$ Cesarean section was performed more in adolescent group compared to group-2 ( $24 \%$ VS $12 \%$ ). These findings are supported by Shuaib A et al, Naz $\mathrm{U}$ and others. ${ }^{16,17}$ Low birth weight neonates, 5-minute Apgar $<7$ and NNU admission were seen more frequently in adolescent pregnancies than those in the adult primigravidas (20.4\% VS
$8 \%, 4 \%$ VS $2 \%$ and $19.2 \%$ VS $8 \%$ respectively) with significant $p$-values of $\leq 0.05$. These findings are supported by studies conducted by $\mathrm{Naz} \mathrm{U}$, Onoh $\mathrm{RC}$ et al and $\mathrm{Naz} \mathrm{S}$ et al respectively. ${ }^{10,13,17}$

Current study is not without short comings. Being a hospital-based study, it may not reveal the precise frequency of the problems in the community. There is a certain need of community based studies with more elaborate exploration of the factors involved.

\section{CONCLUSION}

Adolescent pregnancy is associated with a higher rates of certain obstetric risks like anemia, preterm delivery, pregnancy induced hypertension, instrumental delivery, cesarean section and poor neonatal outcome however the risk of antepartum hemorrhage, postpartum hemorrhage and malpresentation is not greater than adult pregnant mothers.

Copyright@ 30 May, 2016.

\section{REFERENCE}

1. Qazi G. Obstetric characteristics and complications of teenage pregnancy $\mathrm{J}$ Postgrad Med Inst Apr - Jun 2011; 25(2):134-8).

2. Pun KD, Chauhan M. Outcomes Of Adolescent Pregnancy at Kathmandu University Hospital, Dhulikhel, Kavre Kathmandu university medical journal Jan-Mar 2011;9 (33)50-53.

3. Iklaki CU, Inaku JU, Ekabua JE, Ekanem El. Perinatal Outcome in Unbooked Teenage Pregnancies in the University of Calabar Teaching Hospital, Calabar, Nigeria. AEISRN Obstetrics and Gynecology 2012; Article ID 246983.

4. Loaiza E, Liang M. Adolescent pregnancy: A review of the evidence. UNFPA, New York, 2013.

5. Mukhopadhyay P, Chaudhuri RN, and Bhaskar P. Hospital-based Perinatal Outcomes and Complications in Teenage Pregnancy in India. J Health Popul Nutr 2010 Oct; 28(5):494-500.

6. Amoran OE. A comparative analysis of predictors of teenage pregnancy and its prevention in a rural town in Western Nigeria. International Journal for Equity in Health 2012; 11:37.

7. Adeyinka DA, Oladimeji O, Adekanbi TI, Adeyinka FE, Falope Y, Aimakhu C. Outcome of adolescent 
pregnancies in southwestern Nigeria: a casecontrol study. J matern Fetal Neonatal med Aug, 2010; 23(8):785-9.

8. Ayuba II, Gani O. Outcome of teenage pregnancy in the Niger delta of Nigeria. Ethiop j Health Sci. Mar2012; 22(1):45-50.

9. Yasmin G, Kumar A, Parihar B. Teenage Pregnancy - Its Impact on Maternal and Fetal Outcome. International journal of scientific study Mar-2014; 1(6):9-13.

10. Naz S, Parveen R, Bhatti A, Baloch R, Hanif M. teenage pregnancy: (are teenagers a high risk group?). Medical channel Jan-Mar 2010;16(1): 140-143.

11. Talawar S, Venkatesh $G$,. outcome of teenage pregnancy. IOSR Journal of Dental and Medical Sciences May-Jun 2013;6(6):81-83.

12. Derme M, Leoncini E, Vetrano G, Carlomogno L, Aleandri V. Obstetric and perinatal outcomes of teenage pregnant women: a retrospective study.
Epidemiology, biostatistics and public health 2013; 10(4): e8641-44.

13. Onoh RC, Ezeonu PO, Anozie BO, Uzoma CO, Obuna EJ et al. Outcome of teenage pregnancy at a tertiary hospital in Abakaliki Southeast Nigeria. Journal of basic and clinical reproductive sciences 2014;3(1): 2226.

14. Shah N, Khan N, Rohra DK, Ahuja KL, Shuja S et al. Comparision of obstetric outcome among teenage and non-teenage mothers from three tertiary care hospitals of Sindh, Pakistan. JPMA Oct 2011; 61:963.

15. Shuaib AA, Frass KA, Al-Harazi AH, Ghanem NS. Pregnancu outcome of mothers aged 17 or less. Saudi Med J 2011;32(2):166-170.

16. Naz U. Comparison of obstetric outcome in terms of the risk of low birth weight, preterm delivery, cesarean section rate and anaemia in primigravid adolescent and older primigravida. JCPSP 2014.24(2): 131-134.

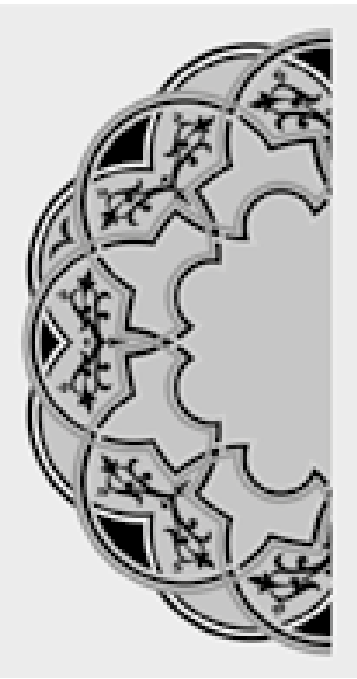

\title{
"Do not regret growing older; it is a privilege denied to many."
}

\author{
Unknown
}

AUTHORSHIP AND CONTRIBUTION DECLARATION

\begin{tabular}{c|l|l|l|}
\hline Sr. \# & \multicolumn{1}{|c|}{ Author-s Full Name } & Contribution to the paper & Author=s Signature \\
\hline 1 & Dr. Quddsia Tanveer & 1st Author \\
\hline 2 & Dr. Anees Fatima & 2nd Author & \\
\hline
\end{tabular}

